\title{
Management of Distribution Risks and Digital Transformation of Insurance Distribution-A Regulatory Gap in the IDD
}

\author{
Pierpaolo Marano 1,2 (D) \\ 1 Faculty of Business, Management and Economics, The University of Latvia, LV-1586 Rīga, Latvia; \\ pierpaolo.marano@lu.lv or pierpaolo.marano@unicatt.it \\ 2 Department of Legal Studies, The Catholic University of the Sacred Heart, 20122 Milan, Italy
}

check for updates

Citation: Marano, Pierpaolo. 2021. Management of Distribution Risks and Digital Transformation of Insurance Distribution-A Regulatory Gap in the IDD. Risks 9: 143. https://doi.org/10.3390/ risks 9080143

Academic Editor: Mogens Steffensen

Received: 28 June 2021

Accepted: 28 July 2021

Published: 2 August 2021

Publisher's Note: MDPI stays neutral with regard to jurisdictional claims in published maps and institutional affiliations.

Copyright: (C) 2021 by the author. Licensee MDPI, Basel, Switzerland. This article is an open access article distributed under the terms and conditions of the Creative Commons Attribution (CC BY) license (https:/ / creativecommons.org/licenses/by/ $4.0 /)$.

\begin{abstract}
The Insurance Distribution Directive (IDD) aims to regulate insurance distribution in the EU regardless of distribution channels and means. Although new technologies affect insurance distribution, the IDD does not explicitly regulate this digital transformation. Insurers and intermediaries must comply with detailed business conduct rules that aim to counteract distribution risks. However, the IDD exempts ancillary insurance intermediaries from its scope when they meet certain conditions. The article highlights the regulatory framework on insurance, requiring insurers and intermediaries to address distribution risks, and analyses how this exemption affects the management of distribution risks in online distribution from a legal perspective. The focus on online distribution depends on the scale such distribution can achieve. The consideration of the scale allows for challenging the political choice behind the exemption of ancillary insurance intermediaries, which consists of the principle of proportionality. A regulatory proposal to counteract these adverse effects is to remove the exemption from the IDD rules for ancillary intermediaries in online distribution. Such a proposal is compliant with the principle of technological neutrality and is in line with the new legislative proposals in the Digital Services Act and Digital Markets Act.
\end{abstract}

Keywords: insurance distribution; digital transformation; Insurance Distribution Directive; distribution risks; insurance distributors; product governance; principle of proportionality; principle of technological neutrality

\section{Introduction}

The EU regulatory framework on insurance requires insurers to identify and manage the risks inherent to the distribution process. Directive 2009/138 of the European Parliament and of the Council of 25 November 2009 on the taking-up and pursuit of the business of Insurance and Reinsurance (Solvency II) supposedly offers consideration of these risks as they can impact insurers from a prudential perspective. Moreover, the proper management of distribution risks prevents detrimental behaviours to customers. The latter directly suffer the detriment resulting from the distribution of poorly designed or inadequately distributed insurance products. Thus, customers would also benefit from the proper risk management of distribution risks in which both insurers and distributors fall into the same rules and supervision. This benefit aligns with the primary objective of the EU insurance regulation and supervision to protect policyholders (see Recital No. 16 and Article 27 of Solvency II). Directive (EU) 2016/97 of the European Parliament and of the Council of 20 January 2016 on insurance distribution (recast) (IDD) supplements Solvency II by introducing detailed business conduct rules addressed to insurers and distributors. In particular, the IDD aims to increase customer protection by strengthening their defence at the point of sale and anticipating the protection of designing insurance products with rules on product oversight and governance. Some of these rules assume a collaboration between insurers and distributors that must comply with the same standards and be supervised by the same authority. Thus, the proper management of distribution risks also depends on the proper functioning of such collaboration. 
The IDD regulates the insurance distribution but only incidentally considered the digital transformation of insurance distribution. The elaboration process of the IDD took place in parallel with this transformation, which is not the core of the IDD rules. In recent years, technological innovation and increasing connectivity supported a digital transformation of distribution channels including those distributing insurance products (Nicoletti 2021; Eling and Lehmann 2018; Stoeckli et al. 2018; Braun and Schreiber 2017; Comanac et al. 2016). Insurers have increased the use of new technologies to distribute directly to current and potential customers (Chrissantis 2016). Many insurance distributors support their business with new technologies (e.g., internet and mobile devices), creating hybrids.

Moreover, new insurance distribution channels arose, such as comparison websites, peer-to-peer insurance, and robo-advisors. In addition, intermediaries who carry out insurance distribution on an ancillary basis to their primary business have enriched the multi-channel nature of insurance distribution. These ancillary intermediaries supplement the offer of their products or services with insurance products, wherein the growing relevance of e-commerce and digital marketplaces integrating third-party vendors moved this cross-selling to online platforms. Therefore, the IDD extended the rules for other insurance distributors to these intermediaries. In principle, ancillary insurance intermediaries collaborate with insurers to manage distribution risks and they are both overseen by the supervisory authority. However, the IDD exempts ancillary insurance intermediaries from the rules applicable to insurance distributors where such intermediaries meet a premium/risk threshold.

The political choice to exempt these intermediaries assumes that the burden deriving from the rules would have been disproportionate to the protection objectives pursued with the introduction of such regulations. Therefore, this choice postulates that the exemption is tolerable; that is, it is compatible with the primary purpose of the EU insurance regulation purposed with protecting policyholders. However, the EU legislation made this assessment without specific consideration of the digital transformation that combines online sales with new technologies (e.g., AI, Big data, and IoT) and software that automate underwriting and claims, thus allowing ancillary intermediaries to reach a scale of their insurance distribution that they would hardly have achieved in face-to-face distribution.

Regulators are identifying and evaluating the challenges of digital transformation to the EU regulatory framework on insurance (EIOPA 2019, 2020a). Scholars have already highlighted some legal and regulatory issues concerning insurance distribution channels arising from this transformation (Anchen et al. 2015; Marano 2016, 2019; Ostrowska and Ziemiak 2020; Fras and Szaraniec 2020; Clemente and Marano 2020; Lima Rego and Carvalho 2020; Tereszkiewicz 2020; Ostrowska and Balcerowski 2021; Tereszkiewicz and Poludniak-Gierz 2021). Moreover, they have also evaluated how the IDD can affect the management of distribution risks (Bravo 2021). However, the literature overlooked the role played by ancillary insurance intermediaries in the management of distribution risks. If the IDD exempts these intermediaries from its rules, managing distribution risks could be more difficult for insurers and detrimental to customers. These intermediaries carry out insurance distribution on an ancillary basis to their primary business. The more the primary business is online, the more the scale of the activity can increase, including the cross-selling of insurance products. Therefore, the present essay analyses the regulatory choice to exempt ancillary insurance intermediaries from the IDD rules. The hypothesis to be investigated concerns whether the exemption is still consistent in the online distribution carried out by ancillary insurance intermediaries, considering the need to manage distribution risks for the insurers and avoid detriments to policyholders. The conclusion is that the consideration of the scale of online distribution allows for challenging the exemption of ancillary insurance intermediaries and calls policymakers to reconsider such an exemption in the upcoming revision of the IDD. 


\section{Materials and Methods}

The first subsection is devoted to listing the distribution risks and introducing the ancillary insurance intermediaries. Their knowledge provides the preliminary background to better understand how the exemption from the IDD rules can affect the management of these risks. Based on a legal approach to the relevant EU regulatory framework on insurance, the analysis outlines the relevance of these risks for insurers and customer protection. Moreover, it describes the definition of ancillary insurance intermediaries and the threshold introduced under the IDD to exempt these intermediaries from its rules.

The second subsection outlines how the IDD addresses distribution risk. The essay uses the analytical method to identify the IDD rules that create business conduct risks to be managed by insurers and distributors. The analysis aims to highlight the relevance of the collaboration between insurers and distributors in managing these risks. The relevance is not limited to these entities. It is also beneficial to the supervisory authority and, above all, to customers. Such knowledge enables one to understand how the exemption from these IDD rules can affect the management of distribution risks and ultimately to appreciate this study's significance.

\subsection{Setting the Scene: Distribution Risks and Ancillary Insurance Intermediaries}

The significance of the risks for insurance undertakings transcends assessing the risk underwritten under each insurance contract. The EU regulatory framework on insurance provides that insurers must be fully aware of the risks they face, including those not related to the underwritten risks.

Solvency II provides that the Solvency Capital Requirement (SCR) must be calibrated to ensure that all quantifiable risks to which an insurance (or reinsurance) undertaking is exposed to are considered. Solvency II describes that the SCR must consider underwriting risks, market risks, credit risks, and operational risks comprising legal risks (see Article 101(4) of Solvency II). Thus, the risks assessment is broader than those inherent in the single insurance coverage (Van Hulle 2019, p. 187). In addition, Solvency II acknowledges that insurers may adequately address some risks only through governance requirements rather than through the quantitative requirements reflected in the SCR. An effective system of governance is essential for the adequate management of the insurance undertaking and the regulatory system (see Recital No. 29 of Solvency II). Therefore, the risk management system of the (re)insurance undertaking must also consider risks that are not (or not entirely) included in the calculation of the SCR (see the risks listed under Article 44(2) of Solvency II). These risks include the actual or potential exposure to reputational and strategic risks and the interrelationship between these risks and other material risks (EIOPA 2015, Guideline 23). Quantitative (SCR) and qualitative (risk management system) requirements allow for achieving the main objective of insurance regulation and supervision in the EU, namely the protection of policyholders and beneficiaries (see Recital No. 16 and Article 27 of Solvency II). The risk assessment is relevant to insurers and their supervisors to verify the state of solvency, establish technical provisions, establish the assets and own eligible funds (see Article 30(2) of Solvency II), and prevent detriments to customers from the design of poor products or mis-selling practices. Indeed, the risk management system of the insurer must manage, monitor, and report the key issues affecting the undertaking's reputation, considering the expectations of stakeholders and the sensitivity of the market (EIOPA 2015, Guideline 23).

The adoption of Solvency II changed the risk profile of the insurance undertaking vis-à-vis the policyholder. Therefore, Solvency II called the European Commission to propose the revision of Directive 2002/92/EC on insurance mediation (IMD), considering the consequences of Solvency II for policyholders (see Recital No. 139 of Solvency II). The Directive (EU) 2016/97 on insurance distribution (IDD) results from this request. The IDD supplements Solvency II by setting forth business conduct rules by placing the relationship between insurers and their customers in higher relevance to identify and manage the related risks. In particular, the IDD aims to increase customer protection by strengthening 
their protection at the point of sale and anticipating such defence at designing insurance products with rules on product oversight and governance. The primary importance of customer protection for the EU insurance regulation and supervision requires careful consideration of the risks arising from the design and distribution of insurance products to the customers.

These risks are qualified as distribution risks and classified as follows: (i) risks to the quality and volume of the insured portfolio caused by actions of the distribution channel; (ii) risks to the insurer's income-generating capacity, long-term financial sustainability, and brand value caused by actions of the distribution channel; and (iii) risks to own distribution channels which ultimately can affect the profitability and sustainability of companies (Gutterman 2016, p. 3; Bravo 2021, p. 356). Regulators have highlighted how these risks can arise from e-commerce (IAIS 2003). In addition, the literature analysed distribution risks from a prudential perspective (Hsin-Chun 2016, pp. 43-50) as they can pose a material risk to an insurer's sustainability, brand value, and income-generating potential (Gutterman 2016, p. 14). The literature also discussed the risk of e-commerce and business conduct regulation (Hsin-Chun 2016, pp. 51-53; Rokas 2016, pp. 17-18; Chrissantis 2016; Abramovsky and Kochenburger 2016) and the implications of introducing the IDD in managing distribution risks in the insurance undertakings by assuming that distribution risks are ultimately the insurer's responsibility, irrespective of the distribution channel used (Bravo 2021, p. 356).

However, the literature did not adequately consider an element relevant to managing these risks in the EU. Insurers are involved in managing the risks associated with the distribution process if their distributors are legally required to comply with the IDD rules and are overseen by the supervisory authority. Although the IDD sets forth business conduct rules to insurers and other distributors, the IDD exempts the ancillary insurance intermediaries from its scope where they meet a premium/risk threshold.

The ancillary intermediaries are any natural and legal person who, for remuneration, takes up or pursues insurance distribution activity on an ancillary basis. It means that they are ancillary where their principal professional activity is activity other than insurance distribution. They only distribute certain insurance products complementary to a good or service; the insurance products concerned do not cover life assurance or liability risks unless that cover complements the good or service that the intermediary provides as its principal professional activity (see Article 2(1)(4) of IDD). These intermediaries fall into the IDD scope but they are exempt from the IDD rules wherein they meet all the following conditions (see Article 1(3) of IDD):

(a) the insurance is complementary to the good or service supplied by a provider, where such insurance covers: (i) the risk of breakdown, loss of, or damage to the good or the non-use of the service supplied by that provider; or (ii) damage to or loss of baggage and other risks linked to travel booked with that provider;

(b) the amount of the premium paid for the insurance product does not exceed EUR 600, calculated on a pro-rata annual basis; and

(c) by way of derogation from point (b) where the insurance is complementary to a service referred to in point (a) and the duration of that service is equal to or less than three months, and the amount of the premium paid per person does not exceed EUR 200.

As a result, when exempt ancillary insurance intermediaries carry out the distribution of insurance products, (i) insurers are not facilitated in managing distribution risks and (ii) customers increase their exposure to these risks, or at least to those risks assuming a collaboration between the insurer and distributor for their management.

The next section outlines how the IDD addresses distribution risks and the relevance of the collaboration between insurers and distributors in managing these risks. 


\subsection{Distribution Risks and the IDD}

In the insurance market, the customers' purchase process depends heavily on intermediaries. A poor risk selection process and inappropriate distribution channel activities are thus expected to have consequences on customer satisfaction, policyholder behaviour, and abnormal lapse rates (Bravo 2021, p. 357).

The IDD addresses distribution risks depending on the distribution channel and the mismanagement of such channel. Risks related to the distribution channel are mis-selling, inappropriate underwriting practices, and choice of inadequate staff. The mismanagement of the distribution channel exposes the channel to reputational risks due to improper selling practices or selecting an inadequate distribution channel or intermediary.

The IDD sets forth the general principle that distributors must always act honestly, fairly, and professionally, in accordance with the best interest of their customers (see Article 17 of IDD), which applies in addition to more detailed conduct of business rules (Köhne and Brömmelmeyer 2018, pp. 728-29). These rules require distributors to sell insurance products with a demands-and-needs test based on the information obtained from the customer (see Article 20 of IDD). Distributors must also provide a product's suitability /appropriateness assessment for insurance-based investment products (see Article 30 of IDD). The rules also concern the conflicts of interest, remuneration and inducements, pre-contractual information, and cross-selling (see Articles 19, 20, 23, 24 28, and 29 of IDD). Moreover, customer protection is achieved through continuous professional training and development requirements to the distributors' employees (see Article 10 of IDD). The latter must maintain an adequate level of knowledge corresponding to the role they perform and the relevant market. In addition, the set of rules on product oversight and governance (POG) (see Article 25 of IDD) requires manufacturers to adopt a product approval process containing measures and procedures for designing, monitoring, reviewing and distributing insurance products, and corrective action for insurance products that are detrimental to customers (see Article 4 of Commission Delegated Regulation (EU) 2017/2359 of 21 September 2017, supplementing the IDD with regard to product oversight and governance requirements for insurance undertakings and insurance distributors).

The literature outlined how: (i) the demands-and-needs test, suitability and appropriateness requirements, and cross-selling provisions are expected to have the most significant impact on sales, distribution, underwriting, and customer management practices; (ii) the remuneration and incentives provisions are expected to impact product manufacturing, sales, and distribution activities significantly; and (iii) the product oversight and governance provisions are expected to impact insurers and intermediaries' product development and distribution activities (Bravo 2021, pp. 359-65).

Most of the duties arising from the rules are addressed to insurers who: (i) must draw up the pre-contractual information document concerning insurance-based investment products (KID) (see Article 5 of Regulation (EU) No. 1286/2014 of 26 November 2014 on key information documents for packaged retail and insurance-based investment products (PRIIPs), and the other insurance products (PID) (see Article 20(6) of IDD) and (ii) cannot make any arrangement by way of remuneration, sales targets, or otherwise that could provide an incentive to distributors or their employees to recommend a particular insurance product to a customer when the insurance distributor could offer a different insurance product that would better meet the customer's needs (see Article 17(3) of IDD).

However, some of the duties refer to distributors. How distributors fulfil these duties affects insurers' ability to supervise and manage the relevant risks. It is the case of the demands-and-needs test, the suitability/appropriateness assessment, and the advice eventually provided to the customer. Insurers can support intermediaries with templates and forms to conduct these activities but this may not happen-e.g., about brokers-and in any case, the duty falls directly to intermediaries. Moreover, insurance distributors cannot remunerate or assess the performance of their employees in a way that conflicts with their duty to act in accordance with the best interests of their customers and they must comply with continuing professional training, development requirements, and must 
be of a good repute. In the case of the cross-selling of insurance and other products or services, as part of a package or the same agreement, the insurance distributor specifies the demands and needs of the customer about insurance products that form part of the overall package or the same agreement. It follows that insurers must have adequate organizational safeguards to monitor the conduct of their distributors if they want to verify timely the proper distribution and compliance with the rules of conduct by the latter (see Article 10(3), of IDD). Thus, insurers must evolve the distribution agreements from agreements of a mainly commercial nature to agreements of an organizational nature to govern the information flows and allow for the controls required to manage distribution risks adequately. Distributors, in turn, have a duty to collaborate with insurance companies and possess an interest in doing so to appropriately manage the distribution risks that also concern themselves as supervised entities.

Indeed, the cooperation between insurers and distributors is paramount for ensuring the proper functioning of the set of rules on POG (Marano 2021, p. 64). These rules provide that the product design consists of identifying the target market and making the product testing, while product monitoring and review requires properly selection and informing and monitoring distribution channels. Furthermore, distributors must cooperate with manufacturers to monitor the distribution of insurance products to the identified target market and organize or apply a specific distribution strategy. Manufacturers and distributors must formalize the cooperation in the product distribution arrangements. In the case of co-manufacturing, the insurer and distributor sign a written agreement that specifies their collaboration to comply with the requirements for manufacturers referred to in the IDD, the procedures through which they shall agree on the identification of the target market and their respective roles in the product approval process (see Article art. 3(4) of Commission Delegated Regulation (EU) 2017/2359 of 21 September 2017, supplementing the IDD with regard to product oversight and governance requirements for insurance undertakings and insurance distributors).

In sum, the number and granularity of the business conduct rules introduced by the IDD increase the distribution risks for insurers and distributors. Therefore, collaboration between these entities is now essential for the proper management of these risks and it is facilitated as both entities must comply with insurance regulation. Moreover, supervisors can receive a clear picture of the distribution and products' governance functioning being as both the insurance and distributor are supervised.

The following section investigates the consequences to insurers and customers where ancillary insurance intermediaries do not fall into the IDD scope and therefore are not required to apply the relevant rules.

\section{Results}

Based on the previous analysis of the adverse effects arising from the exemption of ancillary insurance intermediaries from the IDD rules, this section challenges the exemption in online distribution. The analysis identifies the regulatory principle behind this exemption, which is the principle of proportionality, and demonstrates how online distribution contrasts with the reasons invoked to apply such principle to these intermediaries.

The IDD provides that customers benefit from the same level of protection despite the differences between distribution channels. To guarantee that the same level of protection applies and that the costumers can benefit from comparable standards, especially in disclosing information, a level playing field between distributors is essential (see Recital No. 6 of IDD).

However, the IDD does not apply to persons practising insurance distribution as an ancillary activity where a premium/risk size threshold is met. In this case, an insurance undertaking or insurance intermediary carrying out the distribution activity through an ancillary insurance intermediary that is exempted from the requirements set out in the IDD should ensure the fulfilment of some basic requirements: (i) the communication of its identity and of how the customer can complain; (ii) the demands and needs of the 
customer are considered; (iii) the pre-contractual information document is provided to the customer before the conclusion of the contract; and (iv) appropriate and proportionate arrangements are in place to comply with the provisions of acting in accordance with the best interest of customers and concerning the cross-selling (see Article 1(4) and Recital No. 15 of IDD). It follows that insurers must manage distribution risks from the insurance distribution activities conducted by ancillary intermediaries that are exempted from the IDD but the management could not be supported by the rules established for distributors falling into the IDD scope. Intermediaries that are exempted from the IDD rules are not subject to the supervision of insurance authorities and related administrative sanctions. The collaboration between insurer and distributor does not occur as they are both liable to the insurance supervisory authority. However, only the insurer is responsible to the authority.

EIOPA has been very clear about this responsibility. EIOPA's opinion is that manufacturers of insurance products are expected to apply the POG requirements regarding insurance products distributed by ancillary insurance intermediaries that are exempted from the IDD scope. Manufacturers must (i) provide all appropriate information on the insurance products and the identified target market to these intermediaries, and (ii) adopt adequate procedures to obtain all the information if the product is not in line with the interests, objectives, and characteristics of the identified target market or where other product-related circumstances arise that may adversely affect the customers (EIOPA 2018a).

Moreover, EIOPA's opinion in the case of distribution in the context of group insurance contracts is that the group members are considered customers regarding the application of POG requirements. Consequently, the target market must be defined, considering the features of the insurance product and the needs and objectives of the members, both in the case of compulsory and optional group insurance contracts (EIOPA 2018b). Thus, POG requirements also apply if the group insurance contract is signed and distributed by the exempted insurance ancillary intermediary. In addition, EIOPA stated that POG supervisory activities cover monitoring carried out by manufacturers to ensure that distributors act in line with the objectives of their over-arching POG policy and POG process for specific products. These activities also include whether manufacturers have adequate controls for some distribution channels (e.g., ancillary intermediaries or distance selling). Supervisors must pay particular attention to ancillary insurance intermediaries during the POG assessment to understand how manufacturers monitor these specific intermediaries while considering their ancillary nature and possible risks that could emerge (EIOPA 2020b, p. 15).

Furthermore, the political choice to exempt some intermediaries from the IDD redesigns the supervisory chain on distribution. The IDD sets forth the principle that the supervisory authority monitors both insurers and their distributors and assesses how they work together to comply with the IDD rules. Thus, the supervisor does not suffer any barrier in its relationship with distributors. However, if some distributors are exempted from the vigilance of the authority, the supervisory chain is lengthened. The authority supervises insurers who, in turn, oversee intermediaries that are exempted from complying with the IDD rules. As a result, the supervisor must rely on insurers' supervision of the exempted distributors and customers lose the protection provided by the direct supervision of intermediaries by the authority.

The principle of proportionality would justify such diminished customer protection. Proportionality pertains to drafting the European Union and the Member States' laws (Tridimas 1999, p. 66). Under this principle, a measure adopted by the EU institutions must not exceed the limits of what is appropriate and necessary to achieve the objectives pursued by the legislation in question (Tridimas 2006, p. 137).

The criteria used to exempt from the IDD rules are the premium paid and the risk covered by each insurance contract. These criteria do not consider the number of contracts that each ancillary insurance intermediary can distribute. Nature (risk) and size (premium) of the individual economic relationship (insurance contract) are deemed adequate to 
balance the need for protection and the burden for distributors. In contrast, considering the overall number (scale) of these economic relationships is deemed irrelevant.

It may be that nature and size are adequate more than scale as criteria for identifying the relevance threshold for applying the IDD rules where the distribution is carried out face-to-face. The economic significance of each insurance contract is not associated with the economic importance of the overall number of insurance contracts sold. The lack of consideration of the scale likely depends on considering the intrinsic limits of the faceto-face distribution (on the relevance of the scale for regulatory purposes, Baker and Dellaert 2018, p. 30). This distribution requires establishing relationships that are difficult to repeat in the same way and for large numbers due to the limitations of the time and place in which they take place. The principle of proportionality avoids disproportionate compliance burdens compared to the nature and size of the individual relationship. The scale reachable by all "physical" connections does not alter this assumption. In addition, the distribution activities carried out by the ancillary intermediaries can be challenging to supervise for the authority. The number of such intermediaries and their widespread distribution throughout the territory makes it very difficult for the supervisor to exercise adequate direct supervision on their distribution activities. Therefore, the exemption from the IDD can also be considered an efficiency threshold for the exercise of supervisory tasks. The supervisory burden would be disproportionate even for the authority if it should need to supervise below this threshold.

Considering size and nature as adequate criteria more than scale is coherent with the IDD's regulatory framework which did not put digital transformation at the core of its rules. However, the irrelevance of the scale raises concern to customer protection and distribution risk management when the threshold includes online distribution.

Such distribution makes it possible to reach an indefinite number of people and facilitate cross-border activities of insurers. Standardizing and automating the relationship between distributors and customers allows for repeating the same mistake indefinitely if corrective action is not activated. The collaboration between insurers and some distributors does not occur within uniform rules to which both entities are subject to supervision by the same authority. Compliance with the IDD rules depends on the agreement between insurers and these distributors; that is, the ability of insurers to agree with these distributors on how they must collaborate in managing these risks. This ability depends on the bargaining power of the parties involved. It does not derive from a legal obligation to which these intermediaries must comply. If the balance of power is favourable to the intermediary, the risk is that the latter prefers insurers that are less likely to manage distribution risks by imposing charges on intermediaries.

The exemption threshold may also constitute an incentive for regulatory arbitrage. The higher the compliance costs required of distributors by the IDD, the greater the incentive for intermediaries to evade these costs by distributing products that allow them to stay within the exemption threshold. Thus, intermediaries could push insurers to manufacture insurance products whose premium will enable them to remain within the exemption threshold. Considering the insurance premium calculation mainly depends on the risk underwritten by the insurer, the "need" to comply with the exemption threshold could lead insurers to adverse behaviour towards their customers. Insurers could manufacture products covering a lower risk to those corresponding to the interests and needs of the target market if they must charge a prefixed amount of premium.

Moreover, in the case of distributors carrying out business in a Member State (A) other than the Member State in which the insurer has its head office (B), the supervisory authorities of Member State A cannot activate the supervisory procedures envisaged for the breach of obligations, where distributors are registered as insurance intermediaries. Therefore, customer protection is challenging for the authority of Member State A with the risk of delays in detecting and prohibiting improper sales practices.

Regardless of the intermediary's opportunistic behaviour (and the insurer), the lack of insurance expertise of the exempt ancillary intermediaries is likely to postpone discovering 
the systematic error that depends on the automation of this relationship. Therefore, insurers should monitor this distribution as they still need to identify and manage the related risks under the POG rules.

Ultimately, the exemption from the IDD rules is likely to increase distribution risks for insurers and be detrimental to costumers to a greater extent for online activities than face-to-face activities that the EU legislator has mainly considered.

\section{Discussion-A Regulatory Proposal}

The principle of proportionality justifies the exemption of some ancillary intermediaries from the IDD. This principle can be usefully recalled considering a relationship between the distributor and customer in presence. The burden deriving from the IDD rules would be disproportionate to the nature and size of insurance contracts offered together with other products or services, while the scale can be deemed irrelevant. The last section outlined how this political choice can affect the management of distribution risks by insurers and be detrimental to customers by highlighting how the negative impact is likely to be higher in the online distribution.

A regulatory proposal to counteract these adverse effects is to remove the exemption from the IDD rules for ancillary intermediaries in online distribution. This proposal is consistent with the principle of technological neutrality, which is one of the guiding principles of the Commission's policies on digital innovation (Chatzara 2020, p. 14). This principle aims at repealing legal provisions (i) that are outdated, unnecessary, and/or excessive in the context of changing business models and/or the 'digital' environment, and (ii) where the underlying public policy objectives can be achieved similarly without representing a barrier to innovation.

The proposal to eliminate the exemption in online distribution introduces a different discipline for distributors due to the technological instrument. However, despite this, the proposal does not run counter to the principle of technological neutrality. Such a principle has undergone an evolution that allows it to affirm that the proposal is consistent.

First, technological innovation cannot justify more attenuated rules where the activity carried out is the same as the "traditional" one and the risks it exposes are the same. Given the technological neutrality of legislation, it is not relevant how digitised a company is or which technology it is using. To classify the undertaking, only the nature of the products or services offered and the risks taken by this entity are relevant (EIOPA 2019, p. 34).

Second, the technology-driven innovations that apply to the business cycle of insurance and insurance intermediation activities may lead to gaps other than those of "traditional" activities (OECD 2018, p. 13; EIOPA 2020b, p. 25): technology neutrality does not mean that the technology is neutral (Greenberg 2016).

\section{Conclusions}

Technology can affect the phenomena that have been regulated since the dawn of insurance. The digital technology environment can pose different challenges compared to those governed in the "traditional" environment in which insurance has developed. The ambition of many InsurTech start-ups is to automate the underwriting and intermediation of customers. It may lead to issues other than those that arose without such automation. The evolution of e-commerce and rising attractiveness of the customer's digital journey increases the digital marketplaces and attracts entrepreneurs to offer an insurance product as ancillary to a good or a service which is not insurance, as part of a package or the same agreement. These ancillary insurance intermediaries find such cross-selling as beneficial to their customers and profitable for themselves. However, the scale of their distribution activity increases compared to the one reachable with the cross-selling in presence.

The EU law is already addressing concerns related to the size of online platforms under the next Digital Services Act and Digital Markets Act. Both legislative proposals identify thresholds to apply the obligations to online platforms falling into their scope (see Article 25 of Digital Services Act and Article 3 of Digital Markets Act). Therefore, assessing the 
proportionality of compliance burdens for such intermediaries could be reconsidered due to the size their online businesses can reach. Indeed, this grander scale- the overall number of insurance contracts sold-must be met by greater attention to distribution risks for insurers and customers. In addition, the digital mode allows for the supervisor to exercise supervisory powers remotely, without on-site inspections. Therefore, the exemption as a threshold under which supervision cannot take place effectively is also overcome.

Funding: This research was funded by the Latvian Council of Science, Project DigiSMEs, project number LZP-2020/2-0061.

Institutional Review Board Statement: Not applicable.

Informed Consent Statement: Not applicable.

Conflicts of Interest: The authors declare no conflict of interest. The funders had no role in the design of the study; in the collection, analyses, or interpretation of data; in the writing of the manuscript, or in the decision to publish the results.

\section{References}

Abramovsky, Aviva, and Peter Kochenburger. 2016. Insurance Online: Regulatin and Consumer Protection in a Cyber World. In The "Dematerialized" Insurance. Distance Selling and Cyber Risks from an International Perspective. Edited by Pierpaolo Marano, Ioannis Rokas and Peter Kochenburger. Berlin: Springer, pp. 117-42.

Anchen, Jonathan, Frey Astrid, and Kirova Milka. 2015. Life Insurance in the Digital Age: Fundamental Transformation Ahead, Swiss Re Sigma: 6/2015. pp. 1-39. Available online: http://www.biztositasiszemle.hu/files/201512/sigma6_2015_en.pdf (accessed on 1 August 2021).

Baker, Tom, and Benedict G. C. Dellaert. 2018. Regulating Robo Advice across the Financial Services Industry. Iowa Law Review 103: 713-50. Available online: https://scholarship.law.upenn.edu/cgi/viewcontent.cgi?article=2742\&context=faculty_scholarship (accessed on 1 August 2021). [CrossRef]

Braun, Alexander, and Florian Schreiber. 2017. The Current InsurTech Landscape: Business Models and Disruptive Potential. Study Report. St. Gallen: Institute of Insurance Economics.

Bravo, Jorge M. 2021. IDD and Distribution Risk Management. In Insurance Distribution Directive: A Legal Analysis. Edited by Pierpaolo Marano and Kyriaki Noussia. Berlin: Springer, pp. 349-69.

Chatzara, Viktoria. 2020. FinTech, InsurTech and the Regulators. In InsurTech: A Legal and Regualtory View. Edited by Pierpaolo Marano and Kyriaki Noussia. Berlin: Springer, pp. 3-26.

Chrissantis, Christos S. 2016. Online Sales of Insurance Producus in the EU. In The "Dematerialized" Insurance. Distance Selling and Cyber Risks from an International Perspective. Edited by Pierpaolo Marano, Ioannis Rokas and Peter Kochenburger. Berlin: Springer, pp. 143-66.

Clemente, GianPaolo, and Pierpaolo Marano. 2020. The Broker Model for Peer-to-Peer Insurance: An Analysis of Its Value. Geneva Papers on Risk and Insurance: Issues and Practice. Basingstoke: Springer Nature, pp. 457-81.

Comanac, Andrada, Paola Musile Tanzi, and Fabio Ancarani. 2016. Insurance Companies and E-rketing Activities: An Empirical Analysis in the Italian Market. In The "Dematerialized" Insurance. Distance Selling and Cyber Risks from an International Perspective. Edited by Pierpaolo Marano, Ioannis Rokas and Peter Kochenburger. Berlin: Springer, pp. 85-108.

EIOPA. 2015. Guidelines on the System of Governance. Available online: https:/ /www.eiopa.europa.eu/content/guidelines-systemgovernance_en (accessed on 1 August 2021).

EIOPA. 2018a. EIOPA Q\&A ID. 1615 of 10 July 2018. Available online: https:/ / www.eiopa.europa.eu/content/1615_en?source=search (accessed on 1 August 2021).

EIOPA. 2018b. EIOPA Q\&A ID. 1617 of 10 July 2018. Available online: https:/ / www.eiopa.europa.eu/content/1617_en?source=search (accessed on 1 August 2021).

EIOPA. 2019. Report on Best Practices on Licensing Requirements, Peer-to-Peer Insurance and the Principle of Proportionality in an Insurtech Context. Available online: https:// register.eiopa.europa.eu/Publications/EIOPA\%20Best \%20practices\%20on\%20 licencing\%20March\%202019.pdf (accessed on 1 August 2021).

EIOPA. 2020a. Discussion Paper on the (Re)insurance Value Chain and New Business Models. Available online: https:/ /www.eiopa. europa.eu/content/discussion-paper-reinsurance-value-chain-and-new-business-models-arising-digitalisation_en (accessed on 1 August 2021).

EIOPA. 2020b. EIOPA's Approach to the Supervision of Product Oversight and Governance. Available online: https:/ / www.eiopa. europa.eu/content/eiopa-approach-supervision-product-oversight-and-governance_en (accessed on 1 August 2021).

Eling, Martin, and Martin Lehmann. 2018. The Impact of Digitalization on the Insurance Value Chain and the Insurability of Risks. Geneva Papers on Risk and Insurance: Issues and Practice. Basingstoke: Springer Nature, vol. 43, pp. 359-96. 
Fras, Mariusz, and Monika Szaraniec. 2020. Digital Consultancy, Artificial Intelligence and Smart Contracts in Insurance Distribution. Selected Legal Problems. In Public and Private Law and the Challenges of New Technological and Digital Markets. II. Legal Aspects of FinTech. Edited by Elisabetta Bani, Beata Pachuca-Smulska and Edyta Rutkowska-Tomaszewska. Munich: Warsaw, C.H. Beck, pp. 259-71.

Greenberg, Brad A. 2016. Rethinking Technology Neutrality. Minnesota Law Review 100: 1495-562. Available online: https:/ /ssrn.com/ abstract $=2748932$ (accessed on 1 August 2021).

Gutterman, Sam. 2016. Distribution Risks. In A Risk Book-Governance, Management and Regulation of Insurance Operations. Ottawa: International Actuarial Association. Available online: https://www.actuaries.org/iaa/IAA/Publications/iaa_riskbook/IAA/ Publications/risk_book.aspx (accessed on 1 August 2021).

Hsin-Chun, Wang. 2016. E-commerce and Distribution of Insurance Products: A Few Suggestions for an Apprpriate Regulatory Infrastructure. In The "Dematerialized" Insurance. Distance Selling and Cyber Risks from an International Perspective. Edited by Pierpaolo Marano, Ioannis Rokas and Peter Kochenburger. Berlin: Springer, pp. 39-58.

IAIS. 2003. Risk to Insurers Posed by Electronic Commerce. Issues Paper. Available online: https://www.iaisweb.org/page/ supervisory-material/issues-papers / / file/34284/risks-to-insurers-posed-by-electronic-commerce-july-2003 (accessed on 1 August 2021).

Köhne, Thomas, and Christoph Brömmelmeyer. 2018. The New Insurance Distribution Regulation in the EU-A Critical Assessment from a Legal and Economic Perspective. Geneva Paper on Risk Insurance: Issues and Practice. Basingstoke: Springer Nature, vol. 43, pp. 704-39.

Lima Rego, Margarida, and Joana Campos Carvalho. 2020. Insurance in Today's Sharing Economy: New Challenges Ahead or a Return to the Origins of Insurance. In InsurTech: A Legal and Regualtory View. Edited by Pierpaolo Marano and Kyriaki Noussia. Berlin: Springer, pp. 27-48.

Marano, Pierpaolo. 2016. The EU Regulation on Comparison Websites of Insurance Products. In The "Dematerialized" Insurance. Distance Selling and Cyber Risks from an International Perspective. Edited by Pierpaolo Marano, Ioannis Rokas and Peter Kochenburger. Berlin: Springer, pp. 59-84.

Marano, Pierpaolo. 2019. Navigating InsurTech: The digital intermediaries of insurance products and customer protection in the EU. Maastricht Journal of European and Comparative Law 26: 294-315. [CrossRef]

Marano, Pierpaolo. 2021. The Contribution of Product Oversight and Governance (POG) to the Single Market: A Set of Organizational Rules for Business Conduct. In Insurance Distribution Directive: A Legal Analysis. Edited by Pierpaolo Marano and Kyriaki Noussia. Berlin: Springer, pp. 55-74.

Nicoletti, Bernardo. 2021. Insurance 4.0. Benefits and Challenges of Digital Transformation. Berlin: Springer.

OECD. 2018. Financial Consumer Protection Approaches in the Digital Age. Available online: https:/ /www.oecd.org/finance/G20OECD-Policy-Guidance-Financial-Consumer-Protection-Digital-Age-2018.pdf (accessed on 1 August 2021).

Ostrowska, Marta, and Maciej Balcerowski. 2021. The Idea of Robotic Insurance Mediation in the Light of the European Union Law. In InsurTech: A Legal and Regulatory View. Edited by Pierpaolo Marano and Kyriaki Noussia. Berlin: Springer, pp. 199-210.

Ostrowska, Marta, and Michal Ziemiak. 2020. The Concept of P2P Insurance: A Review of the Literature and EIOPA Report. Warsaw: Prawo Asekuracyjne, pp. 3-48.

Rokas, Ioannis. 2016. European and International Distribution of Insurance Products. In The "Dematerialized" Insurance. Distance Selling and Cyber Risks from an International Perspective. Edited by Pierpaolo Marano, Ioannis Rokas and Peter Kochenburger. Berlin: Springer, pp. 3-38.

Stoeckli, Emanuel, Christian Dremel, and Falk Uebernickel. 2018. Exploring characteristics and transformational capabilities of InsurTech innovations to understand insurance value creation in a digital world. Electronic Market 28: 287-305. [CrossRef]

Tereszkiewicz, Piotr. 2020. Digitalisation of Insurance Contract Law: Preliminary Thoughts with Special Regard to Insurer's Duty to Advise. In InsurTech: A Legal and Regualtory View. Edited by Pierpaolo Marano and Kyriaki Noussia. Berlin: Springer, pp. 127-46.

Tereszkiewicz, Piotr, and Katarzyna Poludniak-Gierz. 2021. Liability for Incorrect Client Personalization in the Distribution of Consumer Insurance. Risks 9: 83. [CrossRef]

Tridimas, Takis. 1999. Proportionality in Community Law: Searching for the Appropriate Standard of Scrutiny. In The Principle of Proportionality in the Laws of Europe. Edited by Evelyn Ellis. Oxford: Hart Publishing.

Tridimas, Takis. 2006. The General Principles of EU Law2. Oxford: Oxford University Press.

Van Hulle, Karel. 2019. Solvency Requirements for EU Insurers. Cambridge: Intersentia. 